\title{
The Berlin Group and the Society for Scientific Philosophy
}

In the late 1920s and early 1930s, the philosopher Hans Reichenbach led a group of likeminded colleagues in Berlin that must count as an independent point of origin of the movement of logical empiricism. Like the Vienna Circle with whom they cooperated on numerous occasions, their concern was to develop a philosophy of science adequate to the latest advances in science itself. Differences of philosophical background and interests, however, resulted in putting different accents by justifying scientific knowledge.

\section{The Berlin Group: Ideas}

The Berlin Group of Logical Empiricism - to be distinguished from the Society for Empirical/Scientific Philosophy (see §3)—originated with Hans Reichenbach’s seminars, held from October 1926 at the University of Berlin. In the spring of 1928, Walter Dubislav joined the Group and soon they met in a special colloquium, led by both of them together. After Reichenbach was forced to emigrate to Istanbul in the summer of 1933 and until the spring of 1935, Dubislav ran it alone. The Group was rather small, its core members being Reichenbach, Dubislav, Kurt Grelling, Alexander Herzberg, and occasionally, also Kurt Lewin and Wolfgang Köhler. Carl Gustav Hempel, Olaf Helmer, Martin Strauss, and Valentin Bergmann were among its younger participants. Paul Oppenheim can be seen as its associate member (see §2).

In contrast to the Vienna Circle, the Berlin Group considered philosophy to be a sound academic discipline. They devoted themselves to logical and epistemological criticism (analysis) of science and mathematics to determine what we really know. Their task was empirical: to isolate and identify ("herauszuschälen") the first principles and truths of human knowledge on the basis of the latest results in mathematics and science. These principles substantiate (ground) human knowledge. It is clear that they change with every new important development in science and mathematics (Dubislav 1929a). In other words, they present a kind of relative a priori. It is worth noticing that determining this relative a priori was already the main objective of Reichenbach's dissertation (Reichenbach 1920a): to complement Immanuel Kant's principles of science - in his case, with the "principle of probability". 
The next task of "natural philosophy" — a term Dubislav and Reichenbach widely usedwas to organize and present the results achieved in science logically and epistemologically. First logically, in the sense that the claims of science have to be put in impeccable logical order and that its concepts have to be correctly constructed and defined. In the 1920s, Reichenbach tried to fulfill this task by way of the axiomatization of physics, and Dubislav, with the help of formal logic, to formulate a consistent theory of definition (1928). Second, scientific results had to be organized epistemologically, in the sense that the logically wellconstructed scientific theories have to be correctly connected to our perceptions and to the physical world of everyday life (Dubislav 1930).

These reorganizations were tasks for philosophers, Reichenbach argued, since "scientific research does not leave a man time enough to do the work of logical analysis" (1951: 123). Scientists are searching for ever-new discoveries and aim to explain these in new theories. The task of analyzing these theories logically and epistemologically is assigned to philosophers. Reichenbach's distinction between the context of discovery - the context in which scientists develop their theories - and the context of justification - the context in which philosophers reflect about their claims (1938: 6-7)—was introduced in this spirit.

The members of the Berlin Group further maintained that science and philosophy have the same source of knowledge: science itself. Philosophy is just general knowledge - to be more exact, knowledge of the general principles and concepts of science that are put in a logically and epistemologically correct form. Grelling presented this project in the clearest form in (1928), in which he understood philosophical knowledge in this sense, regardless of whether it was obtained by a scientist or a philosopher.

The precursor of this approach of the Berlin Group was the Jakob Friedrich Fries Society founded by Leonard Nelson (1882-1927). It met between 1913 and 1921 in Göttingen though it had already existed since 1908 (Peckhaus 1994). The journal of this Society, Abhandlungen der Fries'schen Schule, N.S., in which, Paul Bernays, among others, published four essays, was founded in 1906 and appeared until 1937.

The Berlin Group also followed Ernst Cassirer (as Neurath once noted [1930/31]). Some of its members developed elements of a comparative theory of science (Wissenschaftslehre), particularly Lewin and partly, Reichenbach (in the 1920s, the two were in close contact). In this context Lewin introduced new concepts into science in order to bring to light new and alternative structures. Among these, especially the concept of genidentity (Genidentität), i.e. the persistence of an object of both physics and biology from one point in time to another, 
enjoyed popularity. It was used both in Reichenbach's The Philosophy of Space and Time (1928) and in Carnap's Aufbau (1928). (Later, this concept was also used by Adolf Grünbaum, Bas von Fraassen, Kevin Mulligan and Barry Smith, among others.) Although Reichenbach's program was not identical to Lewin's (Grelling 1928: 98), he adopted some of its aspects. In particular, Reichenbach hoped that the "logical analysis" of different sciences could also bring to light connections between their ever-changing principles (Milkov 2011). Reichenbach followed this idea especially in his manifesto Aims and Methods of the Modern Philosophy of Nature (1931).

Another comparative theorist of science Reichenbach (and also Lewin) collaborated with in the 1920s was Paul Oppenheim. Reichenbach met him in 1921 and soon became one of the first links of a chain of Oppenheim's "scientific fellows". Later links of this chain were Hempel, Grelling, Helmer, Hilary Putnam, and Nicholas Rescher. Around 1929, when the first phase of his philosophical development came to an end (see §3), Reichenbach recommended to Oppenheim the collaboration with his student Hempel.

This brief account shows that the Berlin Group did not have its roots only in Berlin and was not only active between 1928 and 1933. As noted, Reichenbach worked together with Lewin and Oppenheim between 1921 and 1926 when he was still in Stuttgart. After he left Berlin in July 1933, and until the spring of 1935, the Group continued its work under Dubislav's leadership. Then, from 1937 to 1939, Grelling led a “new Berlin Group” in which the logicians and mathematicians Franz Graf von Hoensbroech, Leopold Löwenheim, and Jürgen von Kempski were active (Peckhaus 1994). From 1938 to 1939, Oppenheim, Hempel, and Grelling formed a new chapter of the Berlin Group in Brussels. In the beginning of the 1940s, the so-called "H2O-Group" operated in the USA (\$2). All these circles can be seen as different formations of the Berlin Group (Rescher even maintained that the Pittsburgh Center for Philosophy of Science had its roots in the Berlin Group [2005]).

The profound interest in natural philosophy eventually led the Berlin Group to begin to develop a general philosophy of science of a type that was to survive the later demise of orthodox logical empiricism. Dubislav made the first step in his book Naturphilosophie (1933) and Hempel was the first to understand the new elements of Dubislav's natural philosophy: "The book under review can be better characterized referring to the fact that, in contrast to Schlick's natural philosophy and also to that of Zilsel's, such problems that have the character of - although rather general — specific issues of natural science, like the problem of life, are being given a back seat in favor of a detailed systematic discussion of the logical 
and methodological problems of natural scientific knowledge.” (1934: 760; 1933) In short, Dubislav directed his attention to the "general principles of investigation in the natural sciences" (this is the title of Chapter 4 of Dubislav's book which plays a central role in it). Importantly enough, traces of Dubislav's influence on Hempel can be easily discovered in the latter's influential work, Philosophy of Natural Science (1966).

Reichenbach was deeply impressed by the Vienna Circle's plea for the establishment of a close connection between philosophy and science and for about 10 years after the publication of its manifesto in September 1929, he was engaged in exploring its problems. It is worth remarking, however, that he was less influenced by the specific doctrines of the Vienna Circle but adopted its main themes instead: meaning, verification, truth, empiricism. But Reichenbach approached these themes following his own intuitions. His explorations found expression, in particular, in the book Experience and Prediction (1938), in which he sharply criticized the Vienna Circle's (earlier) way of treating these themes and suggested alternative solutions instead. Reichenbach went back to his own pre-Vienna-Circle subject of investigation - the "logical analysis" of science — only after he relocated to the USA. He did so particularly in his work Philosophical Foundations of Quantum Mechanics (1944).

Working on problems set out by the Vienna Circle, Reichenbach advanced a form of "consistent empiricism" according to which human knowledge is only a product of empirical observations (1951: 259). He believed that it ultimately disproves the claims of the "rationalism" (apriorism). At the same time, his friends Grelling and Dubislav helped him to better understand not only the epistemology but also the tasks of logic (cf. $\S 2$ ). They thus generated in him a strong interest in the problems of logic which found expression in his (1947). All these developments shaped Reichenbach's form of logical empiricism. The influence of the Vienna Circle on Dubislav was even less pronounced. It can only be discerned in Dubislav's concept of "logical behaviorism" (1933: 69), which was nothing more than his interpretation of Neurath's and Carnap's physicalism.

\section{The Berlin Group: Members}

In the preceding section, in which we tried to comprehensively present the main ideas of the Berlin Group, we have seen that Reichenbach and Dubislav were its joint leaders. Unfortunately, Reichenbach is often considered a "one-man orchestra", as the only man who led the Group. This also explains why his philosophy is well presented in the literature (Salmon 1977). Only recently, it has been shown that as the leader of the Berlin Group, 
Dubislav was his equal (Milkov 2015; 2016). To make this point clearer, we begin this section with a review of the cases in which Reichenbach followed Dubislav.

During his short stay as a student at the University of Göttingen in the summer of 1914, the young Dubislav lived in the direct neighborhood of Leonard Nelson. Apparently, at that time, he also came into contact with Nelson's circle. This is supported by the number of references Dubislav made to Jakob Friedrich Fries and Leonard Nelson in his later writings (Dubislav 1926; 1929a). But this also makes it quite possible that he was associated with Grelling, who was Nelson's assistant at the time, and with Reichenbach, who had close contacts with Grelling. However, as a newcomer, Dubislav was perhaps not personally introduced to them.

Be that as it may, in January 1928, Dubislav and Reichenbach still communicated through letters, though both lived in Berlin. Their relationship only changed after Dubislav sent Reichenbach a preliminary version of his essay "Elementarer Nachweis der Widerspruchlosigkeit des Logik-Kalküls" (1929b). There he developed a new kind of truthtables in logic which deeply impressed Reichenbach, and for good reason. Dubislav's innovation helped him to advance a new probability logic, according to which the truthvalues, "true" and "false", are only two points on a continuous scale of validity that measure the level of its probability. It was Dubislav who drew Reichenbach's attention to the importance of logic for his studies, in which, before 1928, he did not show a serious interest. Although he spoke of "logical analysis" of science even in (1920b), he meant with this an axiomatization of science and its epistemological criticism-not logic proper.

Dubislav also helped Reichenbach to better understand and formulate the concept of "coordinating definition". It has to be remembered that Dubislav was a radical formalist in logic and philosophy of mathematics who followed David Hilbert's axiomatic method. Consequentially, he also applied this method in his philosophy of science (Milkov 2016). According to Dubislav, the task of both scientists and philosophers of science is to coordinate the "objects" (i.e. the events, facts, and states of affairs) of the external world with impeccably formed calculation systems. Most importantly, they must unequivocally attach the "objects" to the calculi and also provide rules of interpretation for the resulting system.

It must also be noted that Dubislav and Reichenbach had a common program in ethics which was clearly different from that of the Vienna Circle. Both groups believed that there is no truth in ethics and that the latter does not convey knowledge. But while the Vienna Circle defended different forms of noncognitivism, according to most of which moral judgments are 
primarily an expression of human emotions, Dubislav and Reichenbach claimed that these are implicit commands, and therefore, are related to the logical principles. On this score, too, Dubislav was the trendsetter: he was the first to develop this conception in print (in 1937), only to be followed by Reichenbach 10 years later (1947: 344, 1951: 280ff.).

Another important member of the Berlin Group was Kurt Grelling. There are good grounds to believe that Grelling inspired Reichenbach to deal with probability when both of them were in Göttingen in 1914. This conjecture is also supported by the fact that Grelling's early paper, "The Philosophical Foundations of the Probability Calculus" (1910), defended the objective interpretation of this discipline against Carl Stumpf's subjectivism. In it, Grelling also linked his thoughts on probability to the problem of induction. Importantly enough, these two conceptions were the kernel of Reichenbach's theory of probability throughout his career. Although Grelling and Reichenbach did not meet again between 1914 and 1926, they kept in touch (see ASP HR 015-54-06 and HR 044-06-21). They resumed their regular meetings when Reichenbach moved from Stuttgart to Berlin in October 1926. Grelling had already relocated from Göttingen to Berlin in 1922. In fact, these were the first steps in setting up the Berlin Group proper.

The related positions of Reichenbach and Grelling on the theory of probability were first brought to public attention at the First Conference on the Epistemology of the Exact Sciences in Prague, 1929. In the discussion (Grelling 1930), the two maintained that true science is only possible when it is based on the principle of induction: only the latter can help substantiate scientific predictions. Both resolutely rejected Carnap's and Waismann's-and, eventually, Wittgenstein's - logical conception of probability. From 1936, however, Grelling turned away from Reichenbach's interpretation of the theory of probability and came to agree more with Carnap's. At the same time, he developed original works in formal ontology (Grelling and Oppenheim 1937).

An important contribution of Grelling to the Berlin Group were his translations of four books of Bertrand Russell-The Analysis of Mind (1921), The ABC of Relativity (1925), The Analysis of Matter (1927), and An Outline of Philosophy (1927) - into German between 1927 and 1930, the period when the Berlin Group started its work. It should be considered that these books belong to a particular period of Russell's philosophical development. These are the products of a fresh start in philosophy he made in 1919 after Wittgenstein (and indirectly also Frege) pointed out serious problems in Russell's philosophy of language (Milkov 2013a). In the above-mentioned books, Russell philosophically assessed new developments 
in the field of psychology (notably, Watson's behaviorism) and physics (in particular, Einstein's theory of relativity). Grelling's translations were well known to the members of the Berlin Group and stimulated the discussions they led.

Another member was Alexander Herzberg (1887-1944) who received a PhD in both medicine and philosophy (Schernus 1994). For years, he was a member of the "Deutschen Monisten-Verbundes" (a society of freethinkers which was under the influence of Ernst Haeckel) and made numerous contributions to its journal, Monistischen Monatsheften. As one of the cofounders of the monists' and positivists' Society for Empirical Philosophy, Herzberg was instrumental in the transition of its leadership into the hands of Reichenbach and Dubislav (see § 3). This was one reason why Reichenbach highly appreciated him. But Herzberg was also theoretically well integrated into the Berlin Group whose philosophical program, after all, was interdisciplinary. They were not only interested in the newest developments in physics, medicine, biology, and technology but also in the psychology and the sociology of science.

Reichenbach, in particular, believed that we can analyze science in three different ways. First, through "logical analysis", i.e. through axiomatic, logical and epistemological analysis: this helps to "rationally reconstruct" science, and this is the way Reichenbach himself followed. Second, through psychological analysis: this shows why scientists and philosophers make theoretical mistakes. This was Herzberg's task. His book The Psychology of Philosophers (1926) was important for the Berlin Group exactly in this context. Reichenbach knew quite well that "the psychological root of all rationalism in the wider sense is an extralogical motive ... it is the search for certainty" (1951: 32). Purely on theoretical grounds, rationalism is not defendable, but its appeal is psychologically understandable. Finally, third, we can also make sociological analyses of science. These examine the impact of the social environment on scientific and philosophical theories.

Carl Gustav Hempel is often presented as a close associate of the Vienna Circle (Friedman 2003). This, however, is not the whole truth. Hempel spent the fall term of 1929 as a student at the University of Vienna and, thanks to a letter of recommendation from Reichenbach, attended some sessions of the Vienna Circle. However, Hempel spent much less time in Vienna than in Berlin, where he studied under Reichenbach from 1926 to 1933 and wrote a dissertation on probability, Reichenbach's specialty (Milkov 2013b). It is no coincidence, therefore, that Hempel's most influential idea, the deductive-nomological model of explanations in science, squared well with the leading endeavor of the Berlin Group - to 
justify (to substantiate) human knowledge. It is also no accident that he positively and extensively reviewed all of Reichenbach's books published after 1928 - until 1937 in the Jahrbuch über die Fortschritte in der Mathematik, and then in the Journal of Symbolic Logic.

From 1934 through 1939, Hempel worked with Oppenheim in Brussels as his "scientific secretary". A product of this work is Hempel and Oppenheim (1936). In the fall of 1939, both emigrated to the USA. (Hempel had previously worked at the University of Chicago for nine months in 1937-1938 as Carnap's assistant.) It was in America that, between 1942 and 1944, a new cohort of the Berlin Group came to life - this time at Princeton, where Hempel joined Oppenheim and Helmer (Carnap named it the "H2O Group"). Hempel's most influential papers, "Studies in the Logic of Conformation" (1945) and (with Oppenheim) "Studies in the Logic of Explanation" (1948), reflect this collaboration. The issues they explored were clearly close to Lewin's and Oppenheim's (and partly also to Reichenbach's) program for the comparative theory of science, ranging as they did from the logic of classification and the systematic ordering of science to taxonomy and the theory of ordering concepts, which reflects conceptual isomorphism among different sciences (Rescher 1997).

Olaf Helmer (1910-2011) was the youngest member of the Berlin Group and a close friend of Carl Hempel. He studied under Reichenbach, did his doctoral degree under Dubislav in Berlin in 1934, and then wrote a second dissertation in London in 1936 under Susan Stebbing. In 1937-1938, Helmer worked, together with Hempel, under Carnap's guidance at the University of Chicago. In 1938-1944, he taught mathematics, first at the University of Illinois in Urbana, and then at CUNY. In 1944-1945, he collaborated with Oppenheim.

From 1946 onwards, Helmer worked in the RAND corporation in Santa Monica (California), which he left in 1968 to cofound the Institute for the Future in Palo Alto (California). Between 1973 and 1976, he was a professor for futurology at the University of California in Los Angeles. His younger friend, Nicholas Rescher, remembered Helmer's turn to futurology in the following terms: "Once he became engrossed in matters of prediction and futurology, this replaced all other concerns. He never returned to the work on confirmation and evidentiation that characterized his early interest." (1997: 166).

It does not take much to realize that Helmer's great enthusiasm for futurology also had its roots in the discussions of the Berlin Group and in the conversations he had with his former teacher Reichenbach. Indeed, the craft of making "good predictions" was of primary importance to the latter's epistemology of science. Reichenbach maintained that "the 
ascertainment of a degree of probability by means of an inductive inference" (1951:242) are free posits - and it is important that these posits are well done so that they are confirmed by the upcoming events.

\section{The Society for Scientific Philosophy}

Like the Vienna Circle, which had its public forum in the Ernst Mach Association, the Berlin Group led the open-for-public Berlin Society for Scientific Philosophy. The latter, in turn, had its roots in the Society for Empirical Philosophy but ought to be distinguished from it. The Berlin Society for Empirical Philosophy was founded by the positivist Josef Petzoldt in February 1927 as the Berlin chapter of the International Society for Empirical Philosophy. Georg von Arco, Max Deri, Alexander Herzberg, Reginald Zimmermann, Friedrich Kraus, and August von Parseval were among its founding members. The International Society for Empirical Philosophy itself was organized by the publisher Raymond Schmidt in 1925 in Leipzig, i.e. before Petzoldt started collaborating with it, in support of the journal Annalen der Philosophie, which already had something of a scientific orientation. Initially, that journal was launched in support of the "as if" philosophy of the Neo-Kantian Hans Veihinger.

The Berlin Society for Empirical Philosophy was formally organized, if not officially registered in court records. It defined its activity through lectures and discussions, hosting from 10 to 20 talks per year. Usually, the lectures were attended by 100 to 300 people. It met on Tuesdays at the theatre of the Second Medical Clinic of the famous Charité Hospital in Berlin. (Friedrich Kraus was the director of the clinic.) The very fact that its meetings took place in the medical school indicates the scientific orientation of this philosophical society. But the venue of the Society's lectures also explains why discussions of philosophical problems of medicine and psychology were prominent at its sessions (see Danneberg and Schernus 1994).

In the first year and a half of Petzoldt's Berlin Society, Reichenbach remained skeptical about its viability, formally becoming its member only in October 1928. In fact, it was Dubislav who prompted Reichenbach to take this step. And it was Neurath who urged him, some months later, to take over its presidency. Neurath's idea was a reformed Berlin Society that would be a counterpart—not necessarily a satellite organization—of the Ernst Mach Association (see ASP HR 014-06-31). At just this time, in May 1929, Petzoldt fell ill and resigned as the president of the Society. Reichenbach, however, was still skeptical. Still on 
June 21 he expressed hope to be elected to the Board of the Ernst Mach Association (HR 01406-28) which, he argued, would spread the influence of the Association on the whole Germanophone realm. For some reason, he changed his mind the following week and on June 30, 1929, he wrote to Carnap: "Recently, Dubislav and I were integrated into the Board, where we, together with Herzberg, have the real power" (HR 013-39-34). To be more precise, Reichenbach was elected President (Vorsitzender) of the society, and Dubislav its Secretary (Greschäftsführer).

The next couple of years saw Reichenbach and his friends trying to transform the work of the Society. A clear indication of this is that by the end of 1931, the Society for Empirical Philosophy was renamed the Society for Scientific Philosophy. Together with the change of the Society's name came also a change in the subjects of the lectures presented at it. More specifically, after February 1932, the word "empirical”, or "empiricism", didn't appear in the title of any of the 42 lectures delivered. In contrast, before that point of change, in 67 lectures the word "empirical" occurred 11 times. Apparently, the new format of the Society put more stress on the fact that it explores philosophically problems of science than that its method is empirical. Dubislav and Reichenbach were the heart and soul of the Society for Scientific Philosophy. Altogether, Dubislav made nine presentations at it and Reichenbach, six. Alexander Herzberg, on his part, lectured three times. Grelling and Hempel, in contrast, never gave a lecture to the Society. The latter fact shows once again that the Berlin Group and the Society were two different entities.

The members of the Society largely represented the scientific elite of Berlin but also of other scientific centers in Germany. Most were seasoned researchers and respected authorities in their fields, many of them holding leading positions in prestigious academic departments and institutes. The lineup of lecturers hosted by the Society included no less than four Nobel laureates: Friedrich Kraus, Max von Laue, Otto Meyerhoff, and Wilhelm Oswald.

The Society served as a forum for innovative scientists, like the founder of Gestalt psychology, Wolfgang Köhler, or the brain researcher, Oskar Vogt. It also attracted talented younger interdisciplinary scientists, such as the biologist and systems theorist Ludwig von Bertalanffy from Vienna. To further their own original research programs, these scientists sought out the sort of stimulus to innovative thinking that the Society's philosophically keyed interdisciplinary discussions fostered. And it is not difficult to see as well that these discussions supported the goal of the Berlin Group to determine and exhibit the relative a priori of different sciences. 


\section{References}

ASP HR = Hans Reichenbach Papers, Archive of Scientific Philosophy, University of Pittsburgh.

Danneberg, L., et al. (eds.) (1994) Hans Reichenbach und die Berliner Gruppe, Braunschweig: Vieweg.

Danneberg, L. and Schernus, W. (1994) "Die Gesellschaft für wissenschaftliche Philosophie," in L. Danneberg et al. (eds.), pp. 391-481.

Dubislav, W. (1925/26) “Über das Verhältnis der Logik zur Mathematik,” Annalen der Philosophie und philosophischen Kritik 5: 193-208.

—_(1926) Die Fries'sche Lehre von der Begründung. Darstellung und Kritik, Dömitz: Matting.

_ (1928) “Zur kalkülmäßigen Charakterisierung der Definition,” Annalen der Philosophie und philosophischen Kritik 7: 136-145.

_ (1929a) Zur Methodenlehre des Kritizismus, Langensalza: Herman Beyer.

__ (1929b) "Elementarer Nachweis der Widerspruchslosigkeit des Logik-Kalküls," Journal für die reine und angewandte Mathematik 161: 107-12.

_ (1930) "Über den sogenannten Gegenstand der Mathematik," Erkenntnis 1: 27-48.

_ (1933) Naturphilosophie, Berlin: Junker und Dünnhaupt.

— (1937) “Zur Unbegründbarkeit der Forderungssätze,” Theoria 3: 330-42.

Friedman, M. (2003) "Hempel and the Vienna Circle," Minnesota Studies in the Philosophy of Science 18: 94-114.

Grelling, K. (1910) “Die philosphischen Grundlagen der Wahrscheinlichkeitsrechnung," in Abhandlungen der Fries'schen Schule, N.S., 3: 439-78.

_ (1928) "Philosophy of the Exact Science: its Present Status in Germany," The Monist 38: 97-119.

_ (1930) “Debate about Probability,” Erkenntnis 1: 260-85.

__ (1932) “Bemerkungen zu Dubislavs 'Die Definition',” Erkenntnis 3: 189-200.

Grelling, K., and Oppenheim, P. (1937) “Der Gestalt-Begriff im Lichte der neuen Logik," in Erkenntnis 7: 211-25.

Hempel, C. 1933. "Walter Dubislav, Naturphilosophie,” Jahrbuch über die Fortschritte der Mathematik 59(1): 56-7. 
—_(1934) "Walter Dubislav, Naturphilosophie,” Deutsche Literaturzeitung 55: 759-62.

_ (1945) "Studies in the Logic of Confirmation," Mind 54: 1-26; 97-121.

_ (1966) Philosophy of Natural Science, Englewood Cliffs (NJ): Prentice-Hall.

_ (1993) "Empiricism in the Vienna Circle and in the Berlin Society for Scientific

Philosophy: Recollections and Reflections," Institute of the Vienna Circle Studies 1: 19.

Hempel, C., and Oppenheim, P. (1936) Der Typusbegriff im Lichte der neuen Logik, Leiden: Sijthoff.

— (1948) "Studies in the Logic of Explanation," Philosophy of Science 15: 135-175.

Herzberg, A. (1926) The Psychology of Philosophers, tr. by E. Wareing, London: Kegan Paul, 1929.

Milkov, N. (2011) “Anmerkungen des Herausgebers," in H. Reichenbach, Ziele und Wege der heutigen Naturphilosophie, Hamburg: Felix Meiner, pp. 147-158.

_ (2013a) “The Joint Philosophical Program of Russell and Wittgenstein and Its Demise," Nordic Wittgenstein Review 2: 81-105.

_ (2013b) "Carl Hempel: Whose Philosopher?," in The Berlin Group and the Philosophy of Logical Empiricism, ed. by N. Milkov and V. Peckhaus, Berlin: Springer.

_ (2015) “On Walter Dubislav,” History and Philosophy of Logic 36: 147-61.

— (2016) "Walter Dubislav's Philosophy of Science and Mathematics," HOPOS: The Journal of the International Society for the History of Philosophy of Science 6: 96-116.

Neurath, O. (1930/31) “Historische Anmerkungen,” Erkenntnis 1: 311-14.

Peckhaus, V. (1994) "Von Nelson zu Reichenbach: Kurt Grelling in Göttingen und Berlin,” in Lutz Danneberg et al., pp. 53-86.

Reichenbach, H. (1920a) “A Philosophical Critique of the Probability Calculus,” in id, Selected Essays: 1909-1953, ed. by M. Reichenbach and R. S. Cohen, Dordrecht-Boston: Reidel, 1978, vol. 2, pp. 312-27.

— (1920b) Relativitätstheorie und Erkenntnis a priori, Berlin: Springer.

— (1938) Experience and Prediction, Chicago: Chicago University Press.

— (1944) Philosophical Foundations of Quantum Mechanics, Berkeley: University of California Press.

_ (1947) Elements of Symbolic Logic, New York: Macmillan.

_ (1951) The Rise of Scientific Philosophy, Berkeley: University of California Press. 
Rescher, N. (1997) "H2O: Hempel-Helmer-Oppenheim. An Episode in the History of scientific Philosophy in the 20th Century," Philosophy of Science 64: 779-805.

_ (2005) “The Berlin School of Logical Empiricism and its Legacy,” Erkenntnis 64: 281304.

Salmon, W. C. (1977) “The Philosophy of Hans Reichenbach,” Synthese 34: 5-88.

Schernus, W. (1994) “Alexander Herzberg: Psychologie, Medizin und wissenschaftliche Philosophie," in L. Danneberg et al. (eds.), pp. 33-51.

\section{Further reading}

The first effort to comprehensively present the Berlin Group was made in Danneberg, L., et al. (eds.) (listed above). The paper of L. Danneberg and W. Schernus, published in that book, contains a detailed record of all lectures presented at the Society for Empirical/Scientific Philosophy (pp. 414-81). The first appreciation of the Berlin Group in English was made in N. Milkov and V. Peckhaus (eds.) (listed above). There is also an anthology of the texts of the Berlin Group: N. Milkov (ed.), Die Berliner Gruppe. Texte zum Logischen Empirismus (Hamburg: Felix Meiner, 2015). See also the two papers of Nicholas Rescher as well as the two papers of Milkov on Dubislav (listed above). 